\title{
Climate-Smart Agriculture: Biochar Amendments
}

This fact sheet is the final installment of a four-part climate-smart agriculture series exploring the relationship between carbon farming, soil health, and soil amendments on CA croplands and rangelands. This fact sheet focuses on biochar amendments and previous fact sheets address the benefits of compost and pulverized rock. The series is intended for members of the technical assistance community who advise CA growers on climate-smart agriculture.

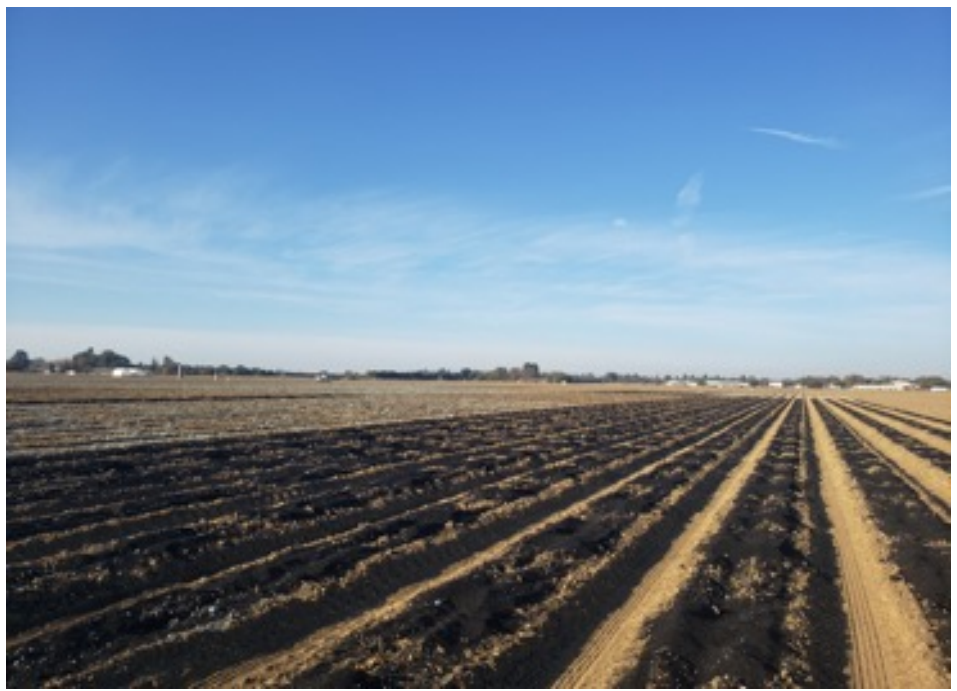

\section{What is biochar?}

There is growing excitement about biochar use as an agricultural amendment to improve soil health and sequester carbon. Biochar is a carbon-rich material, similar to charcoal, made under low oxygen conditions with high temperature conversion of biomass feedstocks such as wood, nutshells, hulls, or manure. In addition to promoting soil carbon storage, biochar may provide benefits to growers such as improved yields and enhanced water and nutrient use efficiency. ${ }^{1-5}$ The potential benefits from biochar are a function of the feedstock and production method, soil type, climate, and cropping system. Although biochar amendments may provide benefits, there are potential drawbacks and growers may need assistance in making informed decisions on how and when to apply biochar to their fields.

\section{How does biochar fit into the big picture in California?}

Development of guidelines for biochar use may be a pathway to reduce overstocked forests of dead and down timber, stimulating forest restoration work in California. Biochar can be made from small diameter trees and woody biomass that has low value as timber or other wood products. Utilizing waste from sustainable forest management can promote activities that reduce wildfire fuel loads, while enhancing forest and soil health.
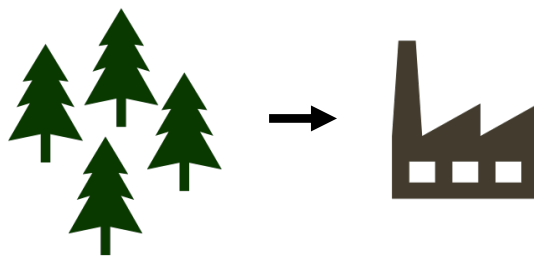

Wood from forest restoration and other waste materials are thermally converted to produce biochar
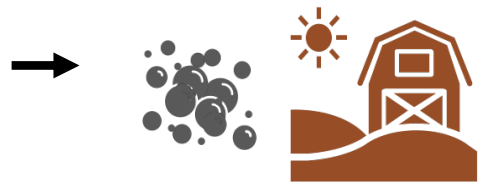

Biochar is applied as a soil amendment, potentially providing benefits to growers and enhancing soil carbon storage

\section{Potential benefits to growers}

Benefits from biochar can be maximized by considering the soil type and the desired outcome from its land application. Typically, benefits of biochar amendments are more often seen in sandy soils, where biochar may increase fertility and improve drought resilience. ${ }^{1}$ Biochar can also have a liming effect in acidic soils, increasing $\mathrm{pH}$ and improving growing conditions. ${ }^{2}$ In clay soils, biochar may reduce bulk density and improve soil workability. ${ }^{3}$ In general, potential benefits include:

Increased yield 2, 4

Improved soil water holding capacity

Increase nutrient retention 5

Reduction of leaching and nutrient runoff 6
Decrease in bulk density ${ }^{7}$

Remediation of polluted soil 8

Synergistic effects when applied with compost ${ }^{9}$

Eligibility for carbon farming-based incentives 


\section{Outstanding questions about using biochar as a soil amendment}

The benefits of biochar can be inconsistent across cropping systems, soil and biochar types. The properties of biochars vary greatly, as there are many possible feedstocks and methods that can be used for its production. To maximize benefits, biochar properties should be matched with soil deficiencies and crop nutrient requirements. At present, there is limited information on which biochars are ideal soil amendments for agronomic benefits and how growers can obtain high-quality biochar. There are also questions about how much biochar can be applied before posing potential risks to growers. Biochar dust may become airborne and present an inhalation hazard to workers who apply or till biochar due to its small particle size (PM10-PM2.5). ${ }^{10}$ Biochar may contain heavy metals or other contaminants, and there are no current regulatory standards for biochar contaminant levels. While potential drawbacks exist, in general biochar has a neutral or positive effect.

\section{Trade-offs with biochar production and use}

There may be trade-offs associated with biochar production and benefits to growers. One example is that the use of certain types of wood waste may not produce biochar with agronomic benefits, which represents a win for waste reduction and carbon sequestration, but does not maximize potential benefits to growers. ${ }^{11}$ A number of long-term biochar field trials are ongoing, and may provide information to aid growers in making informed, science-based decisions about its land application.

Right: Photo showing variation of biochars. Image: UC Davis Biochar Database

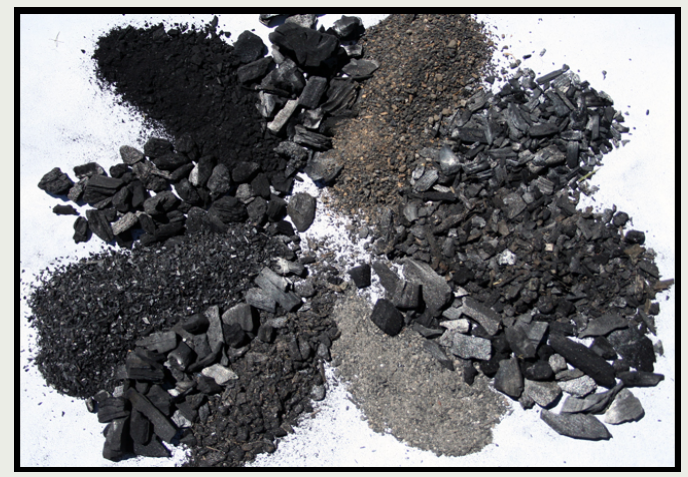

The Working Lands Innovation Center (WLIC) aims to catalyze negative carbon emissions by deploying soil amendment technologies at multi-acre scales in partnership with California researchers, state agencies, industry, farmers, ranchers, Tribes and smallbusiness development. See their website.

\section{Where can growers find more information?}

$>\quad$ USDA Climate Hubs, general information and resources here

$>\quad$ International Biochar Initiative, global biochar resources here

$>\quad$ US Biochar Initiative, biochar use and carbon sequestration here

> UC Davis Biochar Database, properties of biochars here

Pacific Northwest Biochar Atlas, tool for selecting biochars here

$>$ Rodale Institute, soil health and stabilization here

1. Blanco-Canqui, H. (2017). Soil Science Society of America Journal, 81(4), 687-711. doi:10.2136/sssaj2017.01.0017; Abel, S., et al. (2013).

Geoderma, 202-203, 183-191. doi:10.1016/j.geoderma.2013.03.003; Basso, A. S., et al. (2012). GCB Bioenergy, 5(2), 132-143.

doi:10.1111/gcbb.12026

2. Ye, L., et al. (2019). Soil Use and Management, 36(1), 2-18. doi:10.1111/sum.12546

3. Rasa, K., et al. (2018). Biomass and Bioenergy, 119, 346-353. doi:10.1016/j.biombioe.2018.10.004

4. Vaccari, F., et al. (2011). European Journal of Agronomy, 34(4), 231-238. doi:10.1016/j.eja.2011.01.006

5. El-Naggar, A., et al. (2019). Journal of Environmental Management, 241, 458-467. doi:10.1016/j.jenvman.2019.02.044

6. Beck, D. A., et al. (2011). Environmental Pollution, 159(8-9), 2111-2118. doi:10.1016/j.envpol.2011.01.022; Laird, D., et al. (2010).

Geoderma, 158(3-4), 436-442. doi:10.1016/j.geoderma.2010.05.012

7. Burrell, L. D., et al. (2016). Geoderma, 282, 96-102. doi:10.1016/j.geoderma.2016.07.019

8. Shaaban, M., et al. (2018). Journal of Environmental Management, 228, 429-440. doi:10.1016/j.jenvman.2018.09.006

9. Akdeniz, N. (2019). Waste Management, 88, 291-300. doi:10.1016/j.wasman.2019.03.054

10. Gelardi, D. L., et al. (2019). Science of The Total Environment, 678, 813-820. doi:10.1016/j.scitotenv.2019.05.007

11. Jeffery, S., et al. (2013). GCB Bioenergy, 7(1), 1-13. doi:10.1111/gcbb.12132

\section{UCDAVIS
John Muir Institute
of the Environment}

This fact sheet was developed by the USDA California Climate Hub and the Working Lands Innovation Center. Any errors or omissions are the responsibility of the authors and can be directed to the USDA California Climate Hub. The fact sheet was co-authored by Sanjai J. Parikh (UC Davis) and Emilie Winfield (UC Davis, USDA CA Climate Hub) with input from Steven Ostoja (USDA CA Climate Hub). Thank you to Kristin Trippe (USDA ARS) for serving as a reviewer. For fact sheets on other topics related to CA agriculture, please visit https://www.climatehubs.usda.gov/hubs/California. 